\title{
Aldolase of Lactic Acid Bacteria: Immunological Relationships Among Aldolases of Streptococci and Gram-Positive Nonsporeforming Anaerobes
}

\author{
JACK LONDON, NINA M. CHACE, AND KIMBERLY KLINE \\ National Institute of Dental Research, Bethesda, Maryland 20014
}

\begin{abstract}
Antiserum prepared against a Streptococcus faecalis fructose diphosphate aldolase (EC 4.1.2.13) was used to measure the extent of immunological homology between the reference enzyme and aldolases of various streptococci and gram-positive nonsporeforming anaerobic bacteria. The majority of streptococci surveyed were isolated from the oral cavity or blood samples. Strains within the species Streptococcus mutans Clarke and Streptococcus mitis (mitior) possessed aldolases that exhibited marked antigenic heterogeneity and thereby contrasted sharply with previously studied species of Streptococcus (London and Kline, 1973). Varying degrees of cross-reactivity were observed between the aldolases of certain species of Eubacterium, Butyribacterium, and Propionibacterium and the anti-streptococcal aldolase serum. Evidence is also presented confirming an earlier report by Neimark (1974) that aldolases of Acholeplasma species react with the anti-S. faecalis aldolase serum.
\end{abstract}

In a previous study, the fructose diphosphate (FDP) aldolase (EC 4.1.2.13) of Streptococcus faecalis ATCC 27792 (formerly strain MR) was used as a reference point to establish evolutionary relationships among various homofermentative lactic acid bacteria by determining the degree of immunological reactivity between their aldolases and a specific anti-S. faecalis aldolase serum (18). Despite significant differences in the quaternary arrangement of the subunits of this enzyme (17), their primary structure was sufficiently conserved to permit a comparison of their antigenic determinants. A preliminary phylogenetic map of streptococci, lactobacilli, and pediococci was constructed from both qualitative and quantitative immunological data (18).

In the present study, the streptococcal branch of the phylogenetic map is confirmed and extended with new immunological data for aldolases of previously untested strains. Also, immunological heterogeneity has been detected among the aldolases from strains of streptococci within the species Streptococcus mutans and Streptococcus mitis (mitior). The data indicate that neither species is homogeneous. A strong reaction between the aldolase of Butyribacterium rettgeri and anti-S. faecalis aldolase serum prompted the survey reported here for other immunologically related aldolases among grampositive nonsporeforming anaerobic bacteria. The survey includes organisms belonging to the genera Eubacterium, Propionibacterium, and Arachnia.

\section{MATERIALS AND METHODS}

Organisms. The strain designations of the organisms are listed in Table 1. With the exception of strains of $S$. mutans and $S$. mitis (mitior), all cultures of streptococci used in this study were a gift of Richard Facklam (Center for Disease Control); strains of S. mutans and S. mitis (mitior) were obtained from the National Institute of Dental Research Collection and the American Type Culture Collection (ATCC), respectively. Strains of Eubacterium cylindroides were kindly supplied by Lillian Holdeman (Virginia Polytechnic Institute); $B$. rettgeri was provided by Charles Wittenberger (National Institute of Dental Research). All other gram-positive nonsporeforming bacteria and Acholeplasma strains were obtained from the ATCC.

Maintenance and cultivation of the microorganisms. The streptococci were all main. tained on N.I.H. thioglycolate broth (Difco Laboratories, Detroit, Mich.). For enzymological and immunological studies, 2 liters of complex streptococcal medium (16) was inoculated with $10 \mathrm{ml}$ of a 12 -h-old culture of the appropriate organism and incubated at $37 \mathrm{C}$ for $18 \mathrm{~h}$. Cells were harvested by centrifugation and washed twice with cold $0.05 \mathrm{M}$ potassium phosphate buffer, pH 7.0. Washed cell pellets were stored at $-40 \mathrm{C}$ until needed.

Strains of Eubacterium, Butyribacterium, and Arachnia were maintained and cultivated in the prereduced peptone-yeast extract medium of Holdeman and Moore (12) supplemented with $1 \%(\mathrm{wt} / \mathrm{vol})$ glucose. Two-liter batch cultures were grown from a $5 \%$ inoculum in volumetric flasks fitted with pyrogallol $-\mathrm{K}_{2} \mathrm{CO}_{3}$ seals to maintain anaerobiosis at $30 \mathrm{C}$ for 24 to $48 \mathrm{~h}$ and processed as described above.

The propionibacteria were cultured at $30 \mathrm{C}$ in a medium described by van Niel (thesis, Der Tech- 
TABLE 1. Strain designations of organisms

\begin{tabular}{|c|c|}
\hline 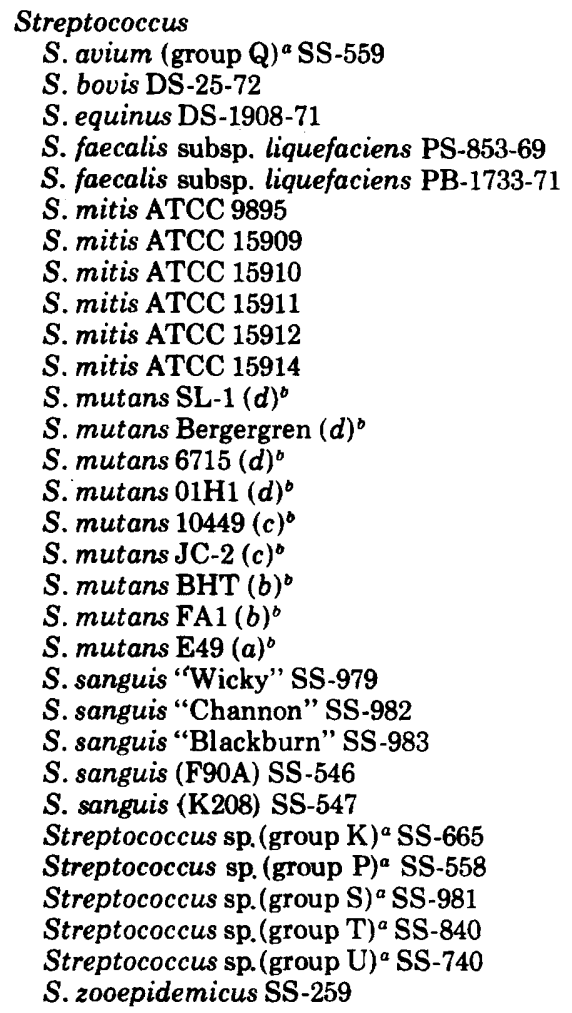 & $\begin{array}{l}\text { Propionibacterium } \\
P . \text { acnes ATCC } 6919 \\
P . \text { freudenreichii ATCC } 6207 \\
P . \text { arabinosum ATCC } 4965 \\
P . \text { intermedium ATCC } 14072 \\
P . \text { jensenii ATCC } 4867,4868 \\
P . \text { pentosaceum ATCC } 4875 \\
P . \text { peterssonii ATCC } 4870 \\
P . \text { rubrum ATCC } 4871 \\
P . \text { thoenii ATCC } 4874 \\
\text { P. zeae ATCC } 4964 \\
\text { Eubacterium } \\
\text { E. limosum ATCC } 8486 \\
\text { E. cylindroides } 3594,3696 \\
\text { E. aerofaciens ATCC } 25986 \\
\text { Acholeplasma } \\
\text { A. granulareum ATCC } 19168 \\
\text { A. laidlawii ATCC } 14089,25937 \\
\text { A. xanthum ATCC } 25176 \\
\\
\text { Listeria } \\
\text { L. grayi ATCC } 25400 \\
\text { L. monocytogenes ATCC } 15313,19111 \\
\text { L. murrayi ATCC } 25401 \\
\text { Others } \\
\text { Arachnia propionica } 14157 \\
\text { Butyribacterium rettgeri ATCC } 10825 \\
\text { Staphylococcus epidermidis ATCC } \\
\text { 155, 14852, 12228 }\end{array}$ \\
\hline
\end{tabular}

\footnotetext{
a Lancefield group antigen.

' Bratthall serotype; the serotype of $S$. mutans strain Bergergren was serotyped by George Hageage (personal communication).
}

nische Hooge School, Delft, The Netherlands, 1928) modified to contain yeast extract, $1 \%(\mathrm{wt} / \mathrm{vol})$, tryptone, $1 \%(\mathrm{wt} / \mathrm{vol})$, and glucose added as a sterile solution to a final concentration of $1 \%$; the $\mathrm{pH}$ was adjusted to 7.2 before sterilization. Strictly anaerobic conditions were not necessary for the cultivation of this group of bacteria. Inoculated screw-cap test tubes filled with medium almost to the brim produced copious growth. Batch cultures were grown in 1-liter screw-cap bottles filled to the neck with medium after inoculation with $10 \mathrm{ml}$ of the appropriate organism. After $24 \mathrm{~h}$ of incubation, the cultures were harvested by centrifugation and treated as above.

Strains of Listeria, Staphylococcus, and Acholeplasma were cultured in media 44, 3, and 243, respectively, as described (1).

Preparation of cell-free extracts. Approximately $4 \mathrm{~g}$ (wet weight) of cell paste was suspended in $10 \mathrm{ml}$ of 2,2-bis(hydroxymethyl)-2',2',2'-nitrilotriethanol buffer, $\mathrm{pH} 6.5$, containing $10 \mathrm{mM} \beta$-mercaptoethanol (BTME) and subjected to ultrasonic disruption in a Branson model 185 sonifier. Operating at $80 \%$ of maximum power, cell suspensions of streptococci were treated for $15 \mathrm{~min}$, and other gram-positive nonsporeforming bacteria and acholeplasma were treated for $8 \mathrm{~min}$. All operations were carried out at $8 \mathrm{C}$. The crude extracts were centrifuged at $30,000 \times g$ for 30 min and the clarified supernatant fluids were decanted. Glycerol was added to all cell-free preparations to a final concentration of $20 \%(\mathrm{vol} / \mathrm{vol})$, and the crude FDP aldolase preparations were stored at $-40 \mathrm{C}$ until used.

Biochemical determinations. The molecular weights of the various aldolases were estimated from their gel filtration profiles on a Sephadex G-200 column $(2.5$ by $95 \mathrm{~cm})$ that had been calibrated with ribonuclease, chymotrypsinogen A, ovalbumin, bovine serum albumin, rabbit muscle aldolase, and human $7 S$ gamma globulin according to the procedure of Andrews (2). After the application of 10 to $20 \mathrm{mg}$ of extract protein, the aldolase activity was eluted from the column with BTME buffer containing $0.1 \mathrm{M} \mathrm{KCl}$ by using the upward-flow technique. The procedures required to obtain accurate and reproducible protein values for crude extracts are described elsewhere (17).

Electrophoretic mobility coefficients of the aldolases were determined on $7.5 \%$ polyacrylamide gel columns. The methods used to prepare the gel columns and the detection of aldolase activity on the columns have been described elsewhere (18). 
Aldolase activity in cell-free extracts was determined spectrophotometric ally according to the procedure of Groves et al. (10). A unit of enzymatic activity is reported as micromoles of FDP cleaved per minute per milligram of protein.

Immunological procedures. The purification of the reference antigen, $S$. faecalis ATCC 27792 FDP aldolase, and the preparation of the anti-aldolase serum have been previously described (18).

Immunodiffusion experiments were performed by using the Stollar and Levine modification (26) of the Ouchterlony double-diffusion technique. Sample wells contained between 0.2 and 0.8 units of aldolase activity, and the center well was charged with sufficient antiserum to produce a sharp precipitin line. The results of immunodiffusion experiments are summarized by using the convention of Gasser and Gasser (9). Discussions dealing with the interpretation of these results have been published elsewhere $(9,18)$ and will not be repeated here.

Micro-complement fixation experiments were carried out according to the procedure of Wasserman and Levine (27); minor modifications of this technique appear elsewhere (19). Guinea pig complement was standardized by the method of Hook and Muschel (13). Anti-aldolase sera were used at a dilution of $1: 75,000$ or $1: 90,000$ with the homologous antigen. Homologous antigen in crude extracts of $S$. faecalis ATCC 27792 was used in the range of 0.8 to $8 \mu \mathrm{g}$ of protein, whereas heterologous antigens were used in concentration ranges as great as 4 to $40 \mu \mathrm{g}$ of protein. Since the comparative amounts of complement fixed by both homologous and heterologous antigens were linear and parallel functions of the logarithm of the antibody concentration (23), data from these experiments were directly comparable. From such data, the index of dissimilarity (ID) was calculated. In those instances where the percentage of complement fixed by the heterologous (het) system was essentially equal to the percentage of complement fixed by the homologous (hom) system $( \pm 10 \%)$, the ID was calculated by the following equation:

$$
\frac{\mathrm{AB} \text { dilution }_{\text {nom }}}{\mathrm{AB} \text { dilution }_{\text {het }}} \times \frac{\% \text { complement fixed }_{\text {nom }}}{\% \text { complement fixed }}
$$

The ID values were also calculated according to the equation of Champion et al. (4); for the aldolase system, the term $m=178$. The ID values obtained by the two equations were comparable to one another only when the percentage of complement fixed by the homologous system was nearly equal to that of the heterologous system. In those instances where it was not possible to raise the antibody concentration sufficiently to make the two values nearly equal, the equation of Champion et al. (4) was used to calculate the ID value. To facilitate a comparison of data from the aldolase study with immunological surveys of other microbial proteins, results of the micro-complement fixation experiments are also expressed as immunological distance units (21) where the immunological distance $=\log \mathrm{ID} \times 100$.

Results of micro-complement fixation and immunodiffusion studies were corroborated with antibody inhibition experiments. Since the anti-aldolase serum contained low but detectable levels of rabbit aldolase the serum was heated at $56 \mathrm{C}$ for $30 \mathrm{~min}$ to destroy all residual enzyme activity. One to $40 \mu \mathrm{l}$ of heated antiserum was added to the previously described enzyme assay mixture (10) and, after a 5-min incubation at ambient temperature, the reaction was started with substrate. Any interaction between aldolase and anti-aldolase serum generally produced an inhibition of enzymatic activity. Such inhibition is indicative of shared structural homology between the heterologous and homologous antigen (enzyme). Serum obtained from the rabbits before immunization served as a control to insure that the enzyme inhibition was specifically induced by the antibodies against the aldolase.

\section{RESULTS}

Biochemical characteristics of aldolase from the gram-positive nonsporeforming anaerobes. In a previous study of the immunologically related aldolases from the lactic acid bacteria, the five groups of aldolase of differing molecular weight were shown to be a manifestation of the five subunit aggregation patterns, which range from dimer to hexamer (17). Although there is only one form of the enzyme within a species, two or three forms have been observed within a genus. Three of the five forms of aldolase have been found among the anaerobes examined in the present study (Table 2). The three forms of the aldolase are found as follows: (i) the relatively large enzyme found in all Propionibacterium species and in Arachnia propionica, whose estimated molecular weight

TABLE 2. Physical characteristics of aldolases from gram-positive nonsporeforming anaerobes

\begin{tabular}{|c|c|c|}
\hline Organism & $\begin{array}{l}\text { Estimated } \\
\text { mol wt of } \\
\text { aldolase }\end{array}$ & $\begin{array}{c}R_{f} \text { of } \\
\text { aldol ase }\end{array}$ \\
\hline Eubacterium aerofaciens ... & 56,000 & 0.78 \\
\hline E. limosum ............ & 61,000 & 0.75 \\
\hline E. cylindroides 3696 & 60,500 & 0.69 \\
\hline E. cylindroides 3594 & 61,000 & 0.69 \\
\hline Butyribacterium rettgeri & 116,000 & 0.56 \\
\hline Propionibacterium jensenii & & \\
\hline ATCC $4867 \ldots \ldots \ldots \ldots$ & 170,000 & 0.36 \\
\hline P. freudenreichii . ..... & 164,000 & 0.36 \\
\hline$P$. intermedium & 180,000 & 0.34 \\
\hline P. peterssonii. . & 200,000 & 0.33 \\
\hline P. zeae ........ & 164,000 & 0.33 \\
\hline P. rubrum ............. & 176,000 & 0.33 \\
\hline$P$. acnes ......... & 200,000 & 0.32 \\
\hline P. thoenii....... & 176,000 & 0.32 \\
\hline$P$. arabinosum ... & 200,000 & 0.32 \\
\hline$P$. pentosaceum & 180,000 & 0.32 \\
\hline Arachnia propionica & 164,000 & 0.34 \\
\hline
\end{tabular}


ranges from 164,000 to 200,000 and which resembles the hexameric form found in most species of pediococci (17); (ii) the 60,000 molecular-weight enzyme found in Eubacterium species, which is similar to the aldolase of streptococci; and (iii) the B. rettgeri enzyme with a molecular weight of 116,000 , whose size is comparable to that of the aldolase found in most lactobacilli.

A classification of these enzymes according to their electrophoretic mobility rates in polyacrylamide gels also produced three distinct divisions (Table 2). This is perhaps not too surprising since the gels act, in part, as molecular sieves and separate these proteins according to their size as well as their net charge. However, this procedure provides a convenient means of distinguishing between three of the four genera studied. Aldolases from species of Eubacterium migrated most rapidly, followed by the $B$. rettgeri aldolase. The aldolases of propionibacteria were the least mobile in anionic gels.

Immunological differentiation of the aldolases from gram-positive nonsporeforming anaerobes. The aldolases of the anaerobes were arranged in the order of their relatedness to the $S$. faecalis reference enzyme by double-diffusion experiments. Results of a number of multiple cross-matches are summarized in Fig. 1. The $B$. rettgeri aldolase exhibits the greatest degree of immunological similarity to the reference enzyme and therefore leads the following order of decreasing antigenic similarity: $B$. rettgeri $>$

S. faecalis

\begin{tabular}{|c|c|c|c|c|c|}
\hline$\wedge$ & \multicolumn{5}{|c|}{ B. rettgeri } \\
\hline$\Lambda$ & $\wedge$ & \multicolumn{4}{|c|}{ E. cylindroides } \\
\hline$\wedge$ & $\wedge$ & $\wedge$ & \multicolumn{3}{|c|}{ E. limosum } \\
\hline$\wedge$ & $\wedge$ & $\wedge$ & $=$ & E. aer & faciens \\
\hline$\wedge$ & $\wedge$ & $\wedge$ & $\Lambda$ & $\wedge$ & $\begin{array}{c}\text { Propionibacterium } \\
\text { species }\end{array}$ \\
\hline
\end{tabular}

Fig. 1. Hierarchy of immunological relatedness among aldolases of gram-positive nonsporeforming anaerobic bacteria. The arrowhead indicates the dom. inant antigen in the cross-match on immunodiffusion plates; a single spur is produced against the well of the less related antigen (a pattern of partial identity). The equal sign indicates that the pairwise match produced a confluent precipitate ( $a$ pattern of identity or apparent identity).
Eubacterium cylindroides $>E$. limosum $=E$. aerofaciens > Propionibacterium species. Although the aldolase of the 10 species of Propionibacterium reacted only weakly with the anti-streptococcal aldolase serum, the precipitin lines in the Ouchterlony plates were confluent with one another, indicating apparent identity. Initially the precipitin lines were concave to the sample well; however, concentrating the antigen twofold so that 2 units of enzyme activity could be conveniently added to the sample well produced arcs convex to the sample well. Extracts containing the $A$. propionica aldolase reacted very weakly with the antialdolase serum to produce a faint hazy precipitate. The weak cross-reaction precluded any meaningful cross-matches with aldolases from the other anaerobic bacteria.

Cross-matches between the $B$. rettgeri aldolase and the aldolases of Streptococcus lactis, Pediococcus acidilactici, Lactobacillus xylosus, and Microbacterium thermosphactum produced double or crossed spurs (Fig. 2). The pattern of nonidentity produced by the crossmatches is indicative of antigenic divergence (9, 18) with regard to the reference protein and necessitates the creation of a new group or evolutionary line to accommodate the aldolases of the Eubacterium, Butyribacterium, and Propionibacterium species.

Quantitative serology of aldolases from gram-positive nonsporeforming anaerobes. With only one exception, the results of the micro-complement fixation experiments and immunodiffusion results allow a corresponding ordering of the species. A clear conflict exists between the results of the two procedures as regards the E. limosum aldolase. Immunodiffusion experiments indicated that $E$. limosum aldolase is antigenically similar to the $E$.

\section{B. rettgeri}

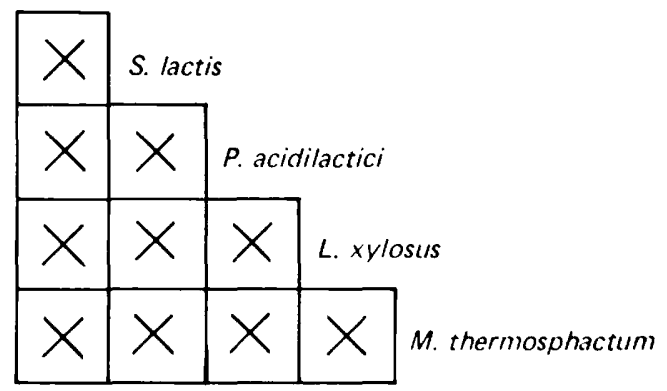

Fig. 2. Reactions of immunological nonidentity produced by five intergeneric cross-matches on Ouchterlony plates. The $\times$ denotes the formation of double spurs when comparing the aldolases of the five bacteria with anti-S. faecalis serum. 
TABLE 3. Results of micro-complement fixation experiments with aldolases of gram-positive, nonsporeforming anaerobes

\begin{tabular}{l|r|c}
\hline \multicolumn{1}{c|}{ Organism } & $\begin{array}{c}\text { Index of } \\
\text { dissimilarity }\end{array}$ & $\begin{array}{c}\text { Immu- } \\
\text { nological } \\
\text { distance }^{a}\end{array}$ \\
\hline Butyribacterium rettgeri & $7.75 \pm 1$ & 89 \\
& $8.2 \pm 1$ & 91 \\
Eubacterium limosum & $33 \pm 6$ & 152 \\
E. cylindroides (3594) & $34 \pm 4$ & 153 \\
E. cylindroides (3696) & $108 \pm 9$ & 208 \\
E. aerofaciens & & \\
Arachnia propionica & 220 & \\
& & \\
Propionibacterium jensenii & $145 \pm 20$ & 216 \\
$\quad$ (4867) & $148 \pm 18$ & 217 \\
P.jensenii (4868) & $185 \pm 21$ & 226 \\
P. zeae & $190 \pm 12$ & 228 \\
P. intermedium & $191 \pm 17$ & 228 \\
P. peterssonii & $212 \pm 14$ & 232 \\
P. pentosaceum & $215 \pm 12$ & 233 \\
\hline
\end{tabular}

${ }^{a} \log$ ID $\times 100$.

aerofaciens enzyme (Fig. 1), whereas microcomplement fixation data indicated that the aldolases of $E$. limosum and $B$. rettgeri are serological equivalents of one another (Table 3 ). The problems inherent in these observations will be discussed later.

Antibody-mediated inhibition studies. To provide additional evidence that the antibodies prepared against the $S$. faecalis aldolase were, in fact, interacting with the immunologically distant aldolases of $A$. propionica and the propionibacteria, aldolase activity in cell-free extracts of these organisms was assayed in the presence and absence of the anti-aldolase serum. Only 2 to $4 \mu \mathrm{l}$ of antiserum was needed to completely inhibit 0.05 units of $S$. faecalis aldolase activity, whereas 30 to $40 \mu$ l of the same antiserum was required to produce a $50 \%$ inhibition of 0.04 to 0.05 units of the aldolase activity present in extracts of Propionibacterium pentosaceum, $P$. thoenii, $P$. freudenreichii, $P$. rubrum, $P$. arabinosum, and $A$. propionica. The addition of $50 \mu \mathrm{l}$ of preimmunized rabbit serum neither enhanced nor inhibited the aldolase activity in the respective extracts.

Immunological characterization of streptococcal aldolases. In the original study, 23 species of Streptococcus were surveyed and assigned to one of five aldolase antigen groups on the basis of their cross-reactivity in immunodiffusion experiments (18). It seemed desirable to extend the present study to include streptococci of interest to medical and dental microbiologists and to examine isolates possessing the less common Lancefield antigens. Figure 3 depicts cross-matches of 13 strains of streptococci and includes as reference points the aldolases from $S$. faecalis (antigen group I), $S$. lactis (antigen group II), Streptococcus bovis (antigen group III), and Streptococcus salivarius (anti-

\section{S. faecalis}

\begin{tabular}{|c|c|c|c|c|c|c|c|c|c|c|c|c|}
\hline 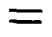 & \multicolumn{12}{|c|}{ S. avium (gp. Q) } \\
\hline$\wedge$ & $\wedge$ & \multicolumn{11}{|c|}{ S. lactis } \\
\hline$\wedge$ & $\wedge$ & $\wedge$ & \multicolumn{10}{|c|}{ S. zooepidemicus (gp C) } \\
\hline$\wedge$ & $\wedge$ & $\wedge$ & $\Lambda$ & \multicolumn{9}{|c|}{ S. bovis } \\
\hline$\wedge$ & $\wedge$ & $\wedge$ & $\Lambda$ & & \multicolumn{8}{|c|}{ S. bovis (variant) ss $25-72$} \\
\hline$\wedge$ & $\wedge$ & $\wedge$ & $\Lambda$ & & $=$ & \multicolumn{7}{|c|}{ group $H$; ss $-546,554,979,982,983$} \\
\hline$\wedge$ & $\wedge$ & $\wedge$ & $\Lambda$ & & $=$ & $=$ & \multicolumn{6}{|c|}{ group K (ss-665) } \\
\hline$\wedge$ & $\wedge$ & $\Lambda$ & 1 & & $=$ & $=$ & $=$ & \multicolumn{5}{|c|}{ group $E$ (ss - 9) } \\
\hline$\wedge$ & $\wedge$ & $\Lambda$ & 1 & & $\wedge$ & $\wedge$ & $\wedge$ & $\wedge$ & S. sa & livar & & \\
\hline$\wedge$ & $\wedge$ & $\wedge$ & 1 & & $\wedge$ & $\wedge$ & $\wedge$ & $\wedge$ & $=$ & S. e & quine & is (DS-1908-71) \\
\hline$\wedge$ & $\wedge$ & $\wedge$ & 1 & & $\wedge$ & $\Lambda$ & $\Lambda$ & $\wedge$ & $=$ & $=$ & grou & $P$ (ss -558$)$ \\
\hline$\wedge$ & $\wedge$ & $\wedge$ & 1 & & $\wedge$ & $\wedge$ & $\wedge$ & $\wedge$ & $=$ & $=$ & $=$ & group S (ss-981) \\
\hline
\end{tabular}

Fig. 3. Results of intra-and interspecific comparisons of 13 streptococcal aldolases on immunodiffusion plates. The symbols are explained in Fig. 1. 
gen group IV) categorized in the earlier work. The aldolase from a Lancefield Q-type Streptococcus appears to be the antigenic equivalent of the $S$. faecalis enzyme. Microorganisms possessing this antigen have already been classified as atypical enterococci, since all $Q$ type isolates also bear the Lancefield group D antigen $(11,25)$; however, the specific epithet Streptococcus avium has been suggested for this group of organisms because they are readily differentiated from the other group D streptococci (20). The aldolase of Streptococcus zooepidemicus cannot be assigned to one of the five original antigenic groupings (18) since it clearly falls between the group $\mathrm{N}$ streptococci (antigen group II) and S. bovis (antigen group III). A comparison of this aldolase and aldolases from other Lancefield group C (animal) streptococci (18) points out yet another difference; all of the other group $\mathrm{C}$ aldolases fall into aldolaseantigen group $\mathrm{V}$. The five strains of group $\mathrm{H}$ streptococci produce lines of identity with one another and with the $S$. bovis aldolase, which places them in antigen group III. A Lancefield group E strain fell into aldolase antigen group III, whereas group $\mathbf{P}$ and $\mathrm{S}$ aldolases were relegated to aldolase antigen group V (Fig. 3).

Aldolases from nine strains of $S$. mutans Clarke were compared with one another and with the aldolases of $S$. bovis ATCC 9809 and Streptococcus pyogenes ATCC 14289. Immunodiffusion experiments segregated the aldolases into two clear and distinct antigenic groups (Fig. 4). The first group, which contains all of the Bratthall (3) serotype $d$ strains, produced

S. bovis

\begin{tabular}{|c|c|c|c|c|c|c|c|c|c|}
\hline$=$ & SL-1 & & & & & & & & \\
\hline$=$ & $=$ & $01 \mathrm{H}$ & & & & & & & \\
\hline$=$ & $=$ & $=$ & K1R & & & & & & \\
\hline$=$ & $=$ & $=$ & $=$ & \multicolumn{2}{|c|}{ Berger gren } & & & & \\
\hline$\wedge$ & $\wedge$ & $\wedge$ & $\wedge$ & $\wedge$ & JC-2 & & & & \\
\hline$\wedge$ & $\wedge$ & $\wedge$ & $\wedge$ & $\wedge$ & $=$ & 10449 & & & \\
\hline$\wedge$ & $\wedge$ & $\wedge$ & $\wedge$ & $\wedge$ & $=$ & $=$ & BHT & & \\
\hline$\wedge$ & $\wedge$ & $\wedge$ & $\wedge$ & $\wedge$ & $=$ & $=$ & $=$ & FA-1 & \\
\hline$\wedge$ & $\wedge$ & $\wedge$ & $\wedge$ & $\wedge$ & $=$ & $=$ & $=$ & $=$ & E4: \\
\hline
\end{tabular}

Fig. 4. Results of cross-matches of nine strains of S. mutans in immunodiffusion experiments. The symbols are defined in Fig. 1. confluent lines of precipitation with $S$. bovis ATCC 9809 (antigen group III). In sharp contrast, the aldolases from Bratthall serotype $a, b$, and $c$ strains produced a pattern of apparent identity with one another and the $S$. pyogenes aldolase (antigen group $\mathrm{V}$ ). The failure of these strains to cluster within a single antigen group as the enterococci, S. bovis, S. salivarius, and Streptococcus sanguis did, suggests that the species $S$. mutans is composed of a heterogeneous collection of streptococci.

The same situation appears to exist within the species $S$. mitis (mitior). Immunodiffusion experiments with aldolases from six of the Williamson $S$. mitis serotypes uncovered three distinct antigenic groups (Fig. 5) that corresponded roughly to aldolase-antigen groups III, IV, and V. These appear in the order: ATCC $15909=$ ATCC $15911=$ ATCC $15912>$ ATCC $15914=$ ATCC $9895>$ ATCC 15910.

Quantitative serology of the streptococcal aldolases. Table 4 lists the indexes of dissimilarity and immunological distances for the streptococcal aldolases as calculated from the results of micro-complement fixation experiments. The ordering of the aldolases was in complete agreement with the immunodiffusion results. However, the increased sensitivity of the former method exposes subtle divergences in the antigenic structure of the respective enzymes that are not apparent from double-diffusion experiments. For example, the aldolase of $S$. faecalis subsp. liquefaciens, which was essentially homologous with the reference $S$. faecalis enzyme, differed significantly from the aldolase of $S$. faecalis subsp. liquefaciens strain

\section{S. faecalis MR}

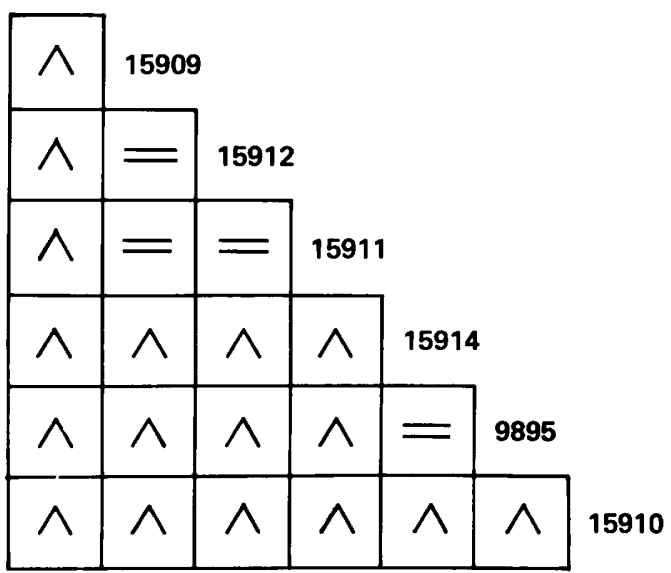

Fig. 5. Results of cross-matches of six strains of $S$. mitis (mitior) in immunodiffusion experiments. The symbols are explained in Fig. 1. 
TABLE 4. Indexes of dissimilarity of streptococcal aldolases

\begin{tabular}{|c|c|c|}
\hline Organism & $\begin{array}{l}\text { Index of } \\
\text { dissimi- } \\
\text { larity }\end{array}$ & $\begin{array}{l}\text { Immuno- } \\
\text { logical } \\
\text { distance }^{a}\end{array}$ \\
\hline $\begin{array}{l}\text { Streptococcus faecalis subsp. } \\
\quad \text { liquefaciens }(835-69)\end{array}$ & $1.06 \pm 0.2$ & 2.5 \\
\hline $\begin{array}{l}\text { S. faecalis subsp. liquefaciens } \\
(1773-71)\end{array}$ & $1.51 \pm 3$ & 18 \\
\hline S. avium group Q (SS-559) & $2.6 \pm 0.4$ & 42 \\
\hline $\begin{array}{l}\text { Streptococcus sp. group K } \\
\text { (SS-665) }\end{array}$ & $22 \pm 3$ & 134 \\
\hline $\begin{array}{l}\text { S. zooepidemicus group C } \\
\text { (SS-259) }\end{array}$ & $27 \pm 3$ & 143 \\
\hline S. bovis variant $(27-72)$ & $30 \pm 5$ & 148 \\
\hline $\begin{array}{l}\text { Streptococcus sp. group U } \\
\text { (SS-740) }\end{array}$ & $49 \pm 5$ & 169 \\
\hline $\begin{array}{l}\text { Streptococcus sp. group P } \\
\quad \text { (SS-558) }\end{array}$ & $70 \pm 13$ & 184 \\
\hline $\begin{array}{l}\text { Streptococcus sp. group T } \\
\quad(\mathrm{SS}-840)\end{array}$ & $88 \pm 9$ & 194 \\
\hline $\begin{array}{l}\text { Streptococcus sp. group S } \\
\quad \text { (SS-981) }\end{array}$ & $98 \pm 7$ & 199 \\
\hline \multicolumn{3}{|l|}{ S. sanguis strains (group $\mathrm{H}$ ) } \\
\hline “Wicky” strain (SS-975) & $30 \pm 4$ & 147 \\
\hline Strain F90A (SS-546) & $32 \pm 5$ & 150 \\
\hline "Channon" strain (SS-982) & $35 \pm 5$ & 154 \\
\hline "Blackburn" strain (SS-983) & $35 \pm 6$ & 154 \\
\hline Strain K208 (SS-547) & $40 \pm 4$ & 160 \\
\hline \multicolumn{3}{|l|}{ S. mutans strains } \\
\hline SL- $1 ;(\text { type } d)^{a}$ & $35 \pm 5$ & 154 \\
\hline Bergergren (type $d$ ) & $41 \pm 2$ & 161 \\
\hline $6715($ type $d)$ & $42 \pm 1$ & 162 \\
\hline$+\mathrm{O} 1 \mathrm{H} 1($ type $d)$ & $45 \pm 5$ & 165 \\
\hline 10449 (type $c$ ) & $85 \pm 5$ & 193 \\
\hline JC-2 (type $c)$ & $85 \pm 6$ & 193 \\
\hline BHT (type b) & $89 \pm 7$ & 195 \\
\hline FA-1 (type b) & $109 \pm 4$ & 204 \\
\hline E-49 (type $a)$ & $131 \pm 7$ & 211 \\
\hline \multicolumn{3}{|l|}{ S. mitis (mitior) strains } \\
\hline ATCC 15909 (type I) $^{b}$ & $18 \pm 1$ & 125 \\
\hline ATCC 15912 (type IV) & $23 \pm 4$ & 136 \\
\hline ATCC 15911 (type III) & $33 \pm 2$ & 152 \\
\hline ATCC 15914 (type VII) & $70 \pm 2$ & 184 \\
\hline ATCC 9895 (type V) & $80 \pm 6$ & 190 \\
\hline ATCC 16910 (type II) & $88 \pm 8$ & 194 \\
\hline
\end{tabular}

${ }^{a}$ Bratthall serotypes.

${ }^{b}$ Williamson serotypes.

1773-71. S. avium, the group Q streptococcus, was clearly differentiable from either of the above organisms. The $S$. sanguis group may also be undergoing diversification; the aldolases of strains "Wicky," "Channon," "Blackburn," and SS-546 exhibit a slightly greater degree of similarity to the reference enzyme than the aldolases of strains SS-547 and ATCC 10556 (18). As expected, the $S$. mitis (mitior) aldol- ases were very heterogeneous, ranging from an ID value of 18 to 88 . Similarly, the distribution of ID values among $S$. mutans aldolases was also very large. It is especially interesting to note that the Bratthall $d$ serotypes clustered as a distinct entity, whereas the $a, b$, and $c$ serotypes were dispersed between ID values of 81 and 131. The significance of this observation will be discussed later.

In addition to the above, Table 4 also lists a number of unspeciated streptococci with distinctive Lancefield group antigens; these data provide the map with loci for the group $\mathrm{P}, \mathrm{T}, \mathrm{S}$, and $U$ antigens. The ID value for the aldolase of a variant of $S$. bovis, strain 27-72, corresponds rather well with those of ATCC strains (18). As expected, the $S$. zooepidemicus aldolase was immunologically distinct from the other group $\mathrm{C}$ streptococci (18). The two strains bearing the Lancefield $\mathrm{K}$ antigen, SS-665 and $S$. mitis ATCC 15910, contrasted with each other in two respects. First, the aldolase of SS-665 had a significantly lower index of dissimilarity than $S$. mitis ATCC 15910, whose ID value was more consonant with those of the $S$. salivarius strains (Lancefield group $\mathrm{K}$ also). Second, an estimation of the size of these two aldolases disclosed that the enzyme from strain SS-665 was typical of the streptococci with an estimated molecular weight of 60,000 . However, S. mitis ATCC 15910 possessed a 130,000 -molecular-weight aldolase that appeared to be unique to strains of $S$. salivarius; it is conceivable that this organism may be a phenotypic variant of this latter species.

Cross-reactions with anti-streptococcal aldolase and aldolases from other bacteria. The aldolases from a number of species belonging to three hitherto untested genera of bacteria were surveyed for cross-reactivity with anti-streptococcal aldolase. Neimark (Abstr. Annu. Meet. Am. Soc. Microbiol., M250, p. 108, 1974) has already published a preliminary report describing the cross-reactions between the anti-S. faecalis aldolase and three species of Acholeplasma, which are in the order Acholeplasma laidlawii $>A$. xanthum $>A$. granularum. Our results confirm his observations. It was the similarity in the FDP activation mechanism of the lactate dehydrogenases found in both the streptococci (H. C. Neimark, Abstr. Int. Assoc. Microbiol., p. 13, 1973) and acholeplasmas that led to an immunological comparison of their aldolases. Therefore, when a report by Schleifer and Kocur (24) appeared recently describing an FDP-activated lactate dehydrogenase from Staphylococcus epidermidis, the aldolases of three strains of this organism were tested for 
cross-reactivity with anti-streptococcal aldolase serum. No cross-reaction between the antiserum and staphylococcal extracts was observed; however, the relatively low levels of aldolase activity may account for the failure to detect an antibody-antigen interaction. The anti-aldolase serum also failed to react with extracts of Listeria murrayi, L. monocytogenes, and $L$. grayi.

\section{DISCUSSION}

The cross-reactions between the anti-S. faecalis aldolase serum and enzyme preparations of certain gram-positive nonsporeforming anaerobes suggest that the aldolases of these organisms share a substantial degree of structural homology with aldolases of the lactic acid bacteria (18). In general, such a finding suggests that both groups of bacteria share a common ancestor. Initially, these observations appear to conflict with the general practice of classifying bacteria according to their phenotypic characteristics, which has, in the past, mandated a distinct separation of Eubacterium, Butyribacterium, and Propionibacterium from genera belonging to the family Lactobacillaceae (12). However, the phenotypic differentiation of these two groups of organisms can be reconciled with the common progenitor hypothesis inferred from the present study if it is assumed that the rate of evolution of different species of proteins is not constant $(8,14)$. Hence, a highly conserved aldolase may evolve far less rapidly than many of the proteins that impart a particular biochemical phenotype to a specific group of microorganisms. This latter event is probably potentiated by environmental pressures that eventually bestow a selective advantage on that group of organisms through the acquisition of new traits.

Deoxyribonucleic acid (DNA) hybridization studies by Johnson (14) established that the nine species of propionibacteria still form a relatively uniform genetic group. The biochemical and serological data reported here support his findings. However, the immunological distance between the reference enzyme and the aldolases of the propionibacteria is so great that minor antigenic differences which might serve to differentiate the respective species cannot be detected. Like the pediococci, the propionibacteria all possess the large form of the aldolase, which presumably is an aggregate of six or more structurally conserved subunits having a molecular weight of 28,000 or 29,500 (17). In contrast to most of the other genera studied, evolutionary alterations affecting the size of the aldolase aggregate have not yet occurred.
The conflicting data that resulted from the immunological characterization of the $E$. limosum aldolase cannot be readily explained, since it is a general practice in our laboratory to use micro-complement fixation assays to confirm and amplify the results of immunodiffusion experiments. Although the micro-complement fixation assay does not directly measure the interaction of antigen and antibody, the complications that usually manifest themselves as "anti-complementary activity" were not apparent in the antigen and antibody controls. This problem is particularly annoying because an unambiguous result would have been useful in resolving the taxonomic status of $B$. rettgeri and $E$. limosum. Holdeman and Moore (12) have suggested that $B$. rettgeri and $E$. limosum are the same organism. Although the microcomplement fixation data support this position, the immunodiffusion data do not. Until more definitive serological evidence is available, the differences in the molecular weights and electrophoretic mobility coefficients of the two aldolases can be used to build a persuasive case for the separation of the two organisms as distinct taxonomic entities. Current studies with another protein marker should resolve this question.

$E$. cylindroides and $E$. aerofaciens, like $E$. limosum, also possess a 60,000-molecularweight aldolase. Although the size of these enzymes closely approximates that found in the majority of the streptococci, it remains to be seen whether the aldolases of these three anaerobes are dimeric aggregates of the smaller 28,000-molecular-weight streptococcal subunit or the larger 29,500 -molecular-weight subunit found in lactobacilli and pediococci (17).

The findings discussed above make it necessary to enlarge the phylogenetic map published earlier (18) to accommodate the gram-positive nonsporeforming anaerobic bacteria. A modified map that integrates the new data on the gram-positive nonsporeforming anaerobic bacteria and presents a more precise alignment of the other related microorganisms based on a comparative study with anti-Pediococcus cerevisiae aldolase sera will be published in the near future.

In the original streptococcal aldolase study, strains of the various species tested were assigned to one of five distinct antigen groups by immunodiffusion cross-match (18). At that time, it was thought that the aldolase of Streptococcus equisimilis ATCC 9598 might serve as the nidus for the sixth and most immunologically distant group. The creation of yet another antigenic group or subgroup may be warranted 
for the placement of the $S$. zooepidemicus aldolase, which appears to be intermediate to group II, the group $\mathrm{N}$ streptococci, and group III, the S. bovis cluster. The correlation between the aldolase antigen grouping and the Lancefield serotypes is good for some species and poor for others. For example, the Lancefield group D, $\mathrm{H}$, and $\mathrm{N}$ streptococci all cluster rather nicely (Fig. 6); exceptions have been cited for the Lancefield group C, K, and E streptococci.

The putative species $S$. mutans Clarke has already been shown to be composed of at least five distinct serotypes (3) and four genotypes (5). Data presented here confirm the heterogeneity of this species. The Bratthall $d$ serotypes appear as an evolutionarily distinct group as compared to the $a, b$, and $c$ serotypes (Fig. 6). Whereas the former cluster among the $S$. bovis and $S$. sanguis strains, the latter are located among and beyond the pyogenic streptococci. It is clear from the cell wall serology, DNA homology, and protein relatedness studies that $S$. mutans is presently populated by a number of divergent groups of organisms that share a significant number of unique phenotypic characteristics $(6,7)$. This paradox may, in part, result from selective pressures acting at two different levels of complexity. Genotypic differences are probably the result of normal mutational events that tend to produce divergence within taxons. However, the highly specialized environment in which these microorganisms must live and compete may impose very stringent conditions upon them that give rise to isologous sets of enzymes and, in turn, produce a homogeneous or convergent phenotype. Gasser and Gasser described a similar situation among the lactobacilli (9). It is apparent, there- fore, that in some instances the taxonomic differences arising from an attempt to use both phenotypic and genotypic characters to define a species such as $S$. mutans are irreconcilable. $S$. mitis (mitior) also appears to be a heterogeneous collection of streptococci. Although DNA pairing data are not yet available, cell wall serology (28) and aldolase similarity studies indicate extreme heterogeneity. The members of this species are spread over much of the aldolase map (Fig. 6).

In addition to accommodating the gram-positive nonsporeforming anaerobes, the relatedness map will also include members of $M y c o-$ plasmatales. Several species of Acholeplasma appear to be closely related to the streptococci (Neimark, Abstr. Int. Assoc. Microbiol., p. 13, 1973; Abstr. Annu. Meet. Am. Soc. Microbiol., M250, p. 108, 1974). The failure to detect cross-reactions between anti-S. faecalis aldolase and extracts of Staphylococcus epidermidis and three species of Listeria does not exclude the possibility that the respective aldolases share some primary sequence homology, since the serological techniques used in these studies can only detect relatively high levels of similarity (22). Finally, it is worth reemphasizing a point made earlier (18). The positions of the various species of bacteria in the aldolasebased phenetic maps are a function of the enzymes' rate of evolutionary change. If another enzyme with the same rate of primary sequence substitution as aldolase were selected as a reference protein, the map positions of the various species of lactic acid would probably remain the same. However, the use of an enzyme whose primary structure is less conserved than that of the aldolase as a reference

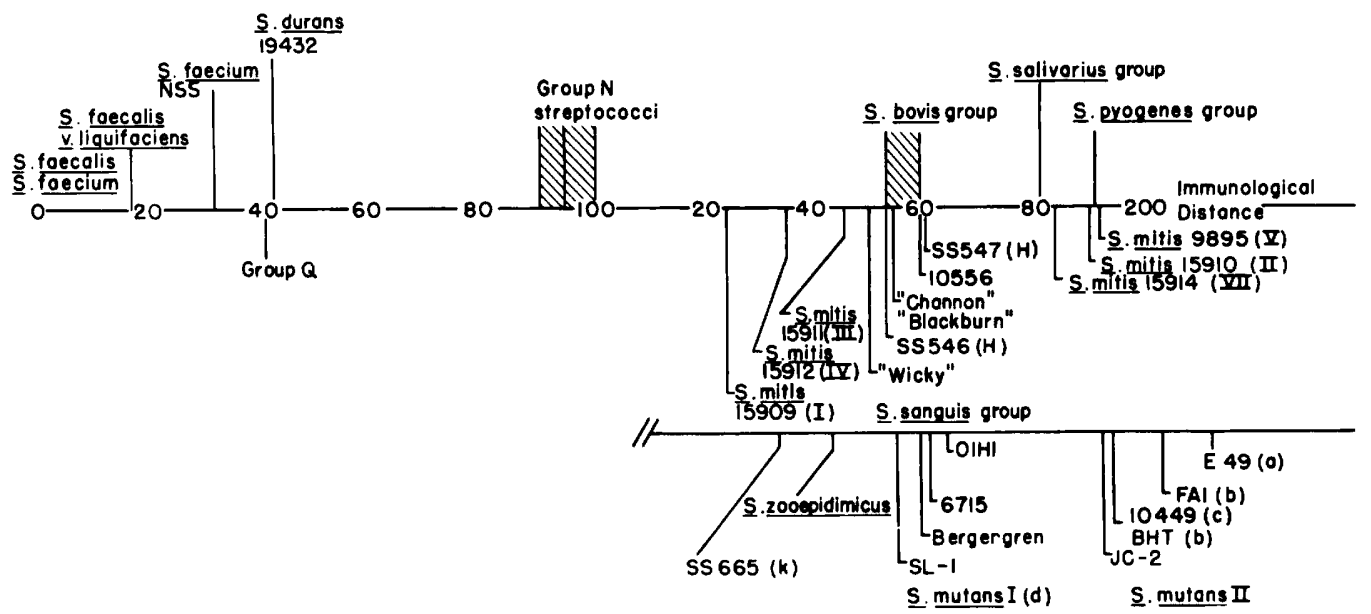

FiG. 6. Streptococcus branch of the proposed phylogenetic map based on antigenic similarities of the FDP aldolase. The lower arm simply shows the position of other organisms in that section of the branch. 
protein would be expected to produce a greater degree of evolutionary divergence and differentiation in a map comprised of the same group of bacteria. In contrast, a more conserved protein would compress and blur the antigenic distinctions observed in the aldolase study and thereby establish closer evolutionary ties within this group of bacteria. A complete appreciation of the phylogenetic relationships between the various species of lactic acid bacteria will not be realized until a number of proteins representing a spectrum of amino acid substitution rates are compared.

\section{REPRINT REQUESTS}

Address reprint requests to: Dr. Jack London, Laboratory of Microbiology and Immunology, National Institute of Dental Research, National Institutes of Health, Bethesda, Md. 20014.

\section{LITERATURE CITED}

1. American Type Culture Collection. 1974. Catalogue of strains, 11th ed. American Type Culture Collection, Rockville, Md.

2. Andrews, P. 1964. Estimation of the molecular weight of proteins by Sephadex gel filtration. Biochem. J. 91:222-233.

3. Bratthall, D. 1970. Demonstration of five serological groups of streptococcal strains resembling Streptococcus mutans. Odontol. Revy 21:143-152.

4. Champion, A. B., E. M. Prager, D. Wachter, and A. C. Wilson. 1974. Microcomplement fixation, p. 397-416 In C. A. Wright (ed.), Biochemical and immunological taxonomy of animals and plants. Academic Press Inc., London.

5. Coykendall, A. L. 1971. Genetic heterogeneity in Streptococcus mutans. J. Bacteriol. 106:192-196.

6. Edwardsson, S. 1968. Characteristics of caries inducing human streptococci resembling Streptococcus mutans. Arch. Oral Biol. 13:637-646.

7. Fitzgerald, R. J. 1968. Plaque and caries. Alabama J. Med. Sci. 5:239-246.

8. Florkin, M. 1966. A molecular approach to phylogeny. Elsevier Publishing Co., Amsterdam.

9. Gasser, F., and C. Gasser. 1971. Immunological relationship among lactic dehydrogenases in the genera Lactobacillus and Leuconostoc. J. Bacteriol. 106:113-125.

10. Groves, W. E., J. Calder, and W. J. Rutter. Fructose diphosphate aldolase. II. Clostridium perfringens, p. 486-491. In S. P. Colowick and N. O. Kaplan (ed.), Methods in enzymology, vol. 9. Academic Press Inc., New York.

11. Guthof, O. 1955. Uber eine Neue Serologische Gruppe $Q$. Zentralbl. Bakteriol. Parasitenk. Infektionskr. Hyg. Abt. 1 Orig. 164:60-69.
12. Holdeman, L. V., and W. E. C. Moore. Anaerobe labora tory manual. VPI Anaerobe Laboratory, Blacksburg. $\mathrm{Va}$.

13. Hook, W. A., and L. H. Muschel. 1964. Anticomplementary effect and complement activity of human sera. Proc. Soc. Exp. Biol. Med. 117:292-297.

14. Johnson, J. L. 1973. Use of nucleic acid homologies in the taxonomy of anaerobic bacteria. Int. J. Syst. Bacteriol. 23:308-315.

15. King, J. L., and T. H. Jukes. 1969. Non-Darwinian evolution. Science 164:788-798.

16. London, J. 1968. Regulation and function of lactate oxidation in Streptococcus faecium. J. Bacteriol. 95: $1380-1387$

17. London, J. 1974. Variations in the quaternary structure of three lactic bacteria aldolases. Evidence for the existence of a class I and class II aldolase in Lactobacillus casei. J. Biol. Chem. 249:7977-7983.

18. London, J., and K. Kline. 1973. Aldolase of lactic acid bacteria: a case history in the use of an enzyme as an evolutionary marker. Bacteriol. Rev. 37:453-478.

19. London, J., E. Y. Meyer, and S. R. Kulczyk. 1971 Detection of relationships between Streptococcus faecalis and Lactobacillus casei by immunological studies with two forms of malic enzyme. J. Bacteriol. 108:196-201.

20. Nowlan, S. S., and R. H. Deibel. 1967. Group Q streptococci. I. Ecology, serology, physiology, and relationship to established enterococci. J. Bacteriol. 94:291-296.

21. Prager, E. M., and A. C. Wilson. 1971. The dependence of immunological cross-reactivity upon sequence resemblance among lysozymes. I. Microcomplement fixation studies. J. Biol. Chem. 246:5798-5989.

22. Prager, E. M., and A. C. Wilson. 1971. The dependence of immunological cross-reactivity upon sequence resemblance among lysozymes. II. Comparison of precipitin and micro-complement fixation resuics. J. Biol. Chem. 246:7010-7017.

23. Sarich, V. M., and A. C. Wilson. 1966. Quantitative immunochemistry and evolution of primate albumins: microcomplement fixation. Science 154:1563-1566.

24. Schleifer, K. H., and M. Kocur. 1973. Classification of staphylococci based on chemical and biochemical properties. Arch. Microbiol. 93:65-85.

25. Smith, D. G., and P. M. F. Shattock. 1964. The cellular location of antigens of Group D, N and Q. J. Gen. Microbiol. 34:165-175.

26. Stollar, D., and L. Levine. 1963. Two-dimensional immunodiffusion, p. 848-854. In S. P. Colowick and N. O Kaplan (ed.), Methods in enzymology, vol. 6. Academic Press Inc., New York.

27. Wasserman, E., and L. Levine. 1961. Quantitative microcomplement fixation and its use in the study of antigenic structure by specific antigen-antibody inhibition. J. Immunol. 87:290-295.

28. Williamson, C. K. 1964. Serological classification of viridans streptococci from the respiratory tract of man In C. A. Leone (ed.), Taxonomic biochemistry and serology, p. 607-622. Ronald Press Co., New York. 